\title{
PENINGKATAN PRODUKTIVITAS USAHA MIKRO TEPUNG SALA DAN SALA MENTAH DI PARIAMAN
}

\author{
Desi Handayani $^{1)}$, Rasyidah Mustika ${ }^{2)}$, Vioni Derosya ${ }^{3)^{*}}$ \\ ${ }^{1)}$ Politeknik Negeri Padang, email: ci_e@yahoo.com \\ ${ }^{2)}$ Politeknik Negeri Padang, email: titik.mustika@gmail.com \\ ${ }^{3)}$ Universitas Andalas, email: vioniderosya@ fateta.unand.ac.id
}

\begin{abstract}
ABSTRAK
Sebagai salah satu ikon kuliner lokal dari Pariaman, Sumatera Barat, sala lauak telah dikembangkan oleh beberapa industri rumahan. Pada awalnya, sala lauak dijual sebagai jajanan pinggir jalan berupa bulatan-bulatan dari nasi, ikan dan rempah-rempah yang kemudian berkembang pula usaha mengolah tepung untuk membuat sala lauak ataupun sala mentah yang dapat digoreng sendiri oleh konsumen. Oleh karena itu, pada IbM kali ini, industri rumah tangga yang dijadikan mitra adalah Tepung Sala Marna yang memproduksi tepung sala dan Sala Asli Piaman Ela yang memproduksi sala mentah dan sala lauak yang sudah digoreng. Pengabdian ini bertujuan untuk meningkatkan manajemen keuangan, optimasi produksi, perbaikan kemasan dalam menjawab tantangan dan permintaan pasar. Kedua mitra dibantu dalam memperbarui kemasan dan alat produksi serta pengurusan PIRT (Pangan Industri Rumah Tangga) sebagai bentuk komitmen mutu dan meningkatkan kualitas.
\end{abstract}

Kata kunci: Sala lauak, Industri rumah tangga, Manajemen keuangan, Akuntansi, Pengemasan

\section{ABSTRACT}

As a typical food from Pariaman, West Sumatera, sala lauak is growing as home industry. In the beginning, sala lauak was only sold as street food made from rice, fish and spices. Nowadays, there is also home industries that produce sala flour and uncooked sala lauak thus consumer can make their own sala lauak at home easily. Thus, there were two home industries as partners in this community service which are 'Tepung Sala Marna' producing sala flour and 'Sala Asli Piaman Ela' producing uncooked sala and fried sala lauak. The project purposes were to improve financial management, optimize production and packaging in order to support these partners in answering market demands. To increase consumer's interest, new design for packaging was added. Further, we also gave technical assistance for both partners in achieving PIRT (Pangan Industri Rumah Tangga) licensed as the prove of quality commitment.

Keywords: Sala lauak, Home industry, Financial management, Accounting, Packaging

\section{PENDAHULUAN}

Sala lauak adalah makanan khas daerah Pariaman berbasis tepung beras dengan tambahan bumbu dan rempah serta ikan yang kemudian dibentuk bulat dan disajikan dengan cara menggoreng. Sala lauak saat ini dijual sebagai tepung sala, sala mentah yang belum digoreng ataupun yang sudah digoreng
[1]. Makanan ini menjadi daya tarik sendiri sebagai kuliner khas dan oleh-oleh Pariaman $[2,3]$. Makanan khas suatu daerah menjadi daya tarik sendiri oleh turis. Selain itu, perantau yang biasanya pulang kampung pada musim Lebaran juga meminati sala lauak untuk dikonsumsi sendiri dan dibawa ke perantauan. 
Sejak tahun 1995, industri rumahan pengolah tepung sala 'Marna' memproduksi dan mengemas tepung sala yang dapat diolah oleh konsumen ataupun penjual sala lauak. Industri ini menyuplai kebutuhan bahan baku pada industri pembuatan makanan tradisional sala lauak di daerah Pariaman dan sekitarnya. Permintaan yang dulunya hanya berasal dari pasar-pasar tradisional kemudian berkembang menjadi permintaan dari pasarpasar modern dan pusat oleh-oleh makanan tradisional.

Selain tepung sala, industri rumahan pengolah sala lauak yang belum digoreng seperti yang dilakukan oleh industri rumah tangga 'Sala Asli Piaman Ela' juga berkembang. Namun, usaha ini masih berkembang seadanya karena keterbatasan alat produksi, manajemen keuangan yang minimalis serta sederhananya kemasan yang digunakan.

Oleh karena itu, usaha ini harus dikelola secara profesional baik dalam skala menengah maupun skala besar untuk menghasilkan produk yang berkualitas dan mampu menjawab permintaan yang tinggi dari konsumen.

Untuk tercapainya permintaan pasar oleh suatu usaha diperlukan manajemen dan perencanaan terstruktur. Perencanaan yang baik serta koordinasi kerja yang rapi memungkinkan untuk tercapainya proses produksi pada tingkat efisien dan efektivitas yang tinggi. Hal ini salah satunya bisa diupayakan dengan menyusun daftar waktu (time schedule) dan administrasi yang baik. Menurut Assauri [3] time schedule yang baik dapat membantu pengusahaan suplai bahan baku dan bahan pembantu yang sesuai dengan kualitas dan kuantitas yang dibutuhkan, dan dapat menyampaikan data atau bahan tersebut sebelum memasuki tahap pengolahan (processing).

Pemilihan mitra dilakukan dengan pertimbangan bahwa mitra ini sudah cukup lama menjalankan kegiatan usahanya, namun masih belum bisa mengembangkannya dikarenakan kendala yang mereka hadapi. Padahal mitra ini memiliki peluang untung mengembangkan usahanya terkait permintaan dari beberapa industri yang cukup terkenal yang tidak bisa dipenuhi. Dengan semakin banyaknya volume permintaan yang harus dipenuhi, manajemen dan pengendalian produksi amatlah penting untuk diterapkan pada usaha ini.

Tidak adanya pembukuan keuangan yang yang baik dan menghasilkan laporan keuangan sesuai standar menyebabkan mitra kesulitan dalam melakukan pinjaman ke bank untuk mengembangkan usahanya. Maka dari itu, laporan keuangan sederhana sangat dibutuhkan oleh setiap jenis usaha, mulai dari usaha berskala kecil sampai skala besar.

Untuk pengemasan produk, tidak ada variasi ukuran dalam pengemasan tepung sala, serta tampilan produk yang sangat sederhana, diperlukan tampilan produk yang 
lebih menarik agar dapat diterima oleh konsumen di pusat perbelanjaan modern.

Beberapa peralatan yang digunakan dalam proses penyangraian tepung dan produksi sala masih sederhana. Untuk itu, pengabdian kali ini bertujuan untuk meningkatkan manajemen keuangan, optimasi produksi, perbaikan kemasan dalam menjawab tantangan dan permintaan pasar.

\section{METODE PELAKSANAAN KEGIATAN}

Metode pelaksanaan Iptek bagi Masyarakat (IbM) kali ini adalah difusi iptek dengan merancang dan membuat alat penyangraian yang baru guna peningkatan produksi tepung sala Selanjutnya, pendidikan masyarakat dalam manajemen pembukuan dan pembuatan laporan keuangan sederhana yang lebih baik. Advokasi dalam pengurusan PIRT juga dilakukan bersamaan dengan pembimbingan terhadap kendala lain yang ditemui.

\section{HASIL DAN PEMBAHASAN}

Kegiatan diawali dengan kunjungan ke Lokasi Mitra 1 yaitu Tepung Sala Marna yang beralamat di Pauh Kambar Kabupaten Padang Pariaman, Sumatera Barat. Dari pertemuan tersebut, anggota tim dapat melihat secara langsung keadaan mitra dalam beraktivitas produksinya.

Kegiatan produksi dilakukan di rumah Ibu Mariatun, dengan bantuan peralatan sederhana dibantu dua orang pekerja. Kegiatan produksi dimulai dari pembelian bahan mentah berupa beras, serta bumbubumbu, penambah cita rasa. Proses produksi dimulai dengan mencuci lalu merendam beras selama satu malam. Beras kemudian ditiriskan lalu disebar di atas tempat yang telah disediakan. Beras yang masih basah tersebut dicampur dengan bumbu yang telah disediakan, Agar beras menyatu dengan bumbu, campuran ini kemudian digiling. Untuk pengeringan, dilakukan penyangraian adonan menggunakan kuali yang berukuran sedang yang dimasak di atas adonan tungku (api yang berasal dari kayu yang dibakar).

Proses penyangraian ini dilakukan sampai adonan tepung tadi kering menggunakan kuali masak seperti pada Gambar 1. Hasil dari penyangraian untuk satu buah kuali lebih kurang sebanyak $3 \mathrm{~kg}$ tepung sala dan menghabiskan waktu sekitar 20 menit serta harus diaduk secara terus menerus, mengingat jika tidak maksimal proses penyangraian ini, hasil tepung jadi tidak bagus. Tepung sala ini dibungkus menggunakan plastik bening ukuran 15 x 25 $\mathrm{cm}$. Bobot tepung $\pm 500 \mathrm{~g}$ dalam tiap kemasan plastik, dengan disertakan aturan/cara memasaknya di selembar kertas. Tepung sala ini dijual dengan harga Rp.10.000,- per kemasan.

Manajemen usaha yang dilakukan oleh Ibu Mariatun masih sangat sederhana. Pemilik hanya menghitung uang masuk dan uang keluar untuk mengetahui keuntungan dari usahanya. Rendahnya tingkat produksi 
mitra ini menyebabkan mitra tidak dapat memenuhi permintaan dari salah satu toko oleh-oleh di Kota Padang.

Terkendala jumlah produksi diduga karena peralatan produksi yang masih sederhana. Untuk itu, Tim Pelaksana Kegiatan menunjuk Tim Pakar untuk mendesain mesin penyangrai tepung sala yang berasal dari Jurusan Teknik Mesin, Politeknik Negri Padang. Alat tersebut memiliki bahan dan desain yang sesuai untuk diterapkan pada mitra yang membutuhkan mesin penyangrai tepung sala untuk meningkatkan jumlah produksi. Dengan menggunakan mesin seperti pada Gambar 2 ini, kapasitas produksi dapat ditingkatkan dari $3 \mathrm{~kg}$ menjadi $5 \mathrm{~kg}$ dalam satu kali penyangraian.

Adapun kemasan tepung sala yang tidak berubah sejak 1995 pun dicoba untuk diperbarui. Dengan menggunakan plastik yang lebih tebal yaitu PVC dan desain kemasan yang baru seperti pada Gambar 3, diharapkan tepung sala ini dapat diterima di pasar modern dan toko oleh-oleh.

Di lain pihak, mitra 2 yaitu Sala Asli Piaman Ela masih menggunakan peralatan memasak biasa dalam proses produksi. Dalam kunjungan tim ke rumah produksi yang berlokasi di Korong Palak Pisang, Nagari Toboh, Kecamatan Sintuk Toboh Gadang, Kabupaten Padang Pariaman, proses produksi dimulai dari pengolahan tepung sala menjadi adonan sala yang siap untuk di goreng dan dinikmati oleh konsumen. Adapun bahan- bahan yang dibutuhkan berupa tepung sala, bumbu-bumbu penambah cita rasa yang telah dihaluskan, ebi dan ikan asin, garam dan irisan daun kunyit. Pembuatan produk dimulai dengan merebus semua bahan dengan air sampai mendidih, lalu tepung sala dimasukkan sesuai takaran yang telah ditetapkan. Adonan diaduk kemudian dibentuk menjadi bola-bola kecil. Uuntuk sala lauak mentah, langsung dilakukan proses pengemasan dengan menggunakan plastik makanan transparan. Sementara itu, untuk sala lauak goreng dilakukan proses penggorengan dulu sebelum dikemas.

Dalam bentuk kemasan yang lama, sala mentah hanya dapat bertahan \pm 12 jam. Dengan alat vacuum sealer yang diberikan pada mitra 2 ini seperti pada Gambar 4, sala mentah dapat disimpan hingga 2 hari sehingga distribusi dan penjualan produk yang awalnya hanya untuk di dalam kota, sekarang dapat melayani permintaan dari luar kota. Tampilan kemasan menggunakan alat vacuum sealer dengan desain kemasan terbaru ditampilkan pada Gambar 5.

Dari kedua mitra tersebut, pencatatan akuntansi belum dilakukan sehingga mereka mengalami kesulitan dalam menghitung laba/rugi usaha dan mengetahui bagaimana kondisi keuangannya. Harga jual produk pun belum dapat dipastikan keuntungannya. Hal ini menyebabkan mitra kesulitan jika 
melakukan pinjaman ke bank untuk $\mathrm{kg}$ tepung sala. Berikut tabulasi perhitungan mengembangkan usahanya, karena tidak HPP tepung sala "Marna".

adanya dokumen keuangan yang dimiliki oleh pemilik. Maka dari itu, kedua mitra mendapatkan bimbingan langsung terkait perhitungan harga pokok produksi (HPP) untuk menentukan harga jual pasti dari suatu produk.

Harga pokok produksi memiliki unsur biaya bahan baku, biaya tenaga kerja langsung, dan biaya overhead atau biaya tak langsung seperti biaya bahan penolong [7]. Diharapkan, kedua mitra nantinya dapat menentukan lebih baik jarga jual produk, memantau realisasi biaya produksi, menghitung laba rugi secara berperiode dan menentukan harga pokok persediaan produk jadi dan produk dalam proses [8]. Selain itu, mitra juga dapat menyusun langkah selanjutnya dalam penetrasi pasar berdasarkan HPP ini.

Dalam menghitung HPP untuk kedua mitra, metode yang dilakukan adalah wawancara langsung. Mitra pertama yaitu Tepung Sala Marna mempunyai kapasitas produksi per hari adalah $40 \mathrm{~kg}$ beras. Namun, proses produksi berlangsung hanya 4 hari dalam satu minggu. Untuk itu, perhitungan HPP dilakukan per hari produksi. Adapun harga bahan baku dari pembuatan tepung sala ini adalah Rp. 500.000,- dengan biaya tenaga kerja langsung adalah Rp. 120.000,-. Sehingga, total HPP adalah Rp. 666.546,per $40 \mathrm{~kg}$ beras yang berarti Rp. 16.664 per
Tabel 1. Perhitungan Harga Pokok Produksi (HPP) “Tepung Sala Marna” per $40 \mathrm{~kg}$

\begin{tabular}{ll}
\hline \multicolumn{1}{c}{ Komponen } & \multicolumn{2}{c}{ Harga } \\
\hline Biaya Bahan Baku: & Rp. $480.000,-$ \\
- Beras & Rp. $6.000,-$ \\
- Bawang Putih & Rp. $10.600,-$ \\
- Cabe & Rp. $3.500,-$ \\
\cline { 2 - 2 } - Kunyit & Rp. \\
Total Biaya Bahan Baku & 500.000,-- \\
\hline Biaya Tenaga Kerja & Rp. 120.000- \\
&, \\
\hline Biaya overhead & \\
- Plastik & Rp. $16.000,-$ \\
- Stiker & Rp. $16.000,-$ \\
- Gas & Rp. $5.500,-$ \\
- Listrik & Rp. $6.250,-$ \\
- Penyusutan peralatan & Rp. $2.796,-$ \\
\cline { 2 - 2 } Total Biaya overhead & Rp. \\
& $\mathbf{4 6 . 5 4 6 , - -}$ \\
\hline HPP & Rp. \\
& $\mathbf{6 6 6 . 5 4 6 , -}$ \\
\hline
\end{tabular}

Untuk mitra kedua, Sala Asli Piaman Ela, Perhitungan HPP dilakukan per $1 \mathrm{~kg}$ bahan dimana biaya bahan baku adalah Rp.8.200,- dengan biaya tenaga kerja atau upah Rp. 7.900,- dan biaya overhead untuk biaya kemasan, gas dan listrik adalah $\mathrm{Rp}$. 3.100,- sehingga HPP adalah Rp. 19.200,-Agar mendapatkan keuntungan dengan margin sebesar 25\% dari HPP, maka nilainya adalah Rp. 4.800,-. Oleh karena itu, harga jual menjadi Rp. 24.000,- per kg untuk sala lauak mentah. Adapun rincian komponen harga pokok produksi disajikan pada Tabel 2 berikut: 
Tabel 2. Perhitungan Harga Pokok Produksi (HPP) Sala Mentah "Sala Asli Piaman Ela"

\begin{tabular}{ll}
\hline \multicolumn{1}{c}{ Komponen } & \multicolumn{1}{c}{ Harga } \\
\hline Biaya Bahan Baku: & \\
- Tepung beras & Rp. 5.400,- \\
- Ebi & Rp. 1.700,- \\
- Cabe & Rp. 700,- \\
- Bawang dan bumbu & Rp. 400,- \\
\cline { 2 - 2 } Total Biaya Bahan Baku & Rp. 8.200,- \\
\hline Biaya Tenaga Kerja & Rp. 7.900-, \\
\hline Biaya overhead & Rp. 2.000,- \\
- Plastik & Rp. $600,-$ \\
- Stiker & Rp. $300,-$ \\
- Gas & Rp. 200,- \\
- Listrik & Rp. 3.100,- \\
Total Biaya overhead & Rp. 19.200,- \\
\hline HPP & \\
\hline
\end{tabular}

Selanjutnya, dalam pengurusan PIRT untuk kedua mitra ditemui beberapa kendala. Hal ini terkait dengan persyaratan pengurusan PIRT yang mengharuskan mitra mengikuti pelatihan terlebih dahulu. Lalu, setiap proses pengurusan PIRT melibatkan beberapa instansi seperti perangkat desa, camat dan Yandu sebelum dilakukan survei ke lokasi mitra oleh dinas terkait. Adapun salah satu tahapan pengurusan PIRT terlihat pada Gambar 6.

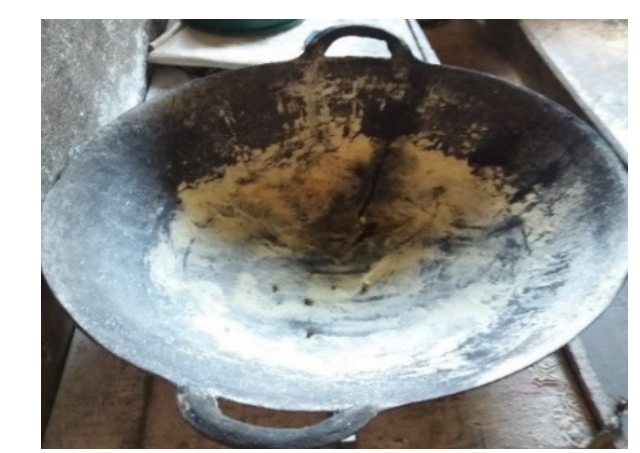

Gambar 1. Peralatan Penyangraian Tepung Sala

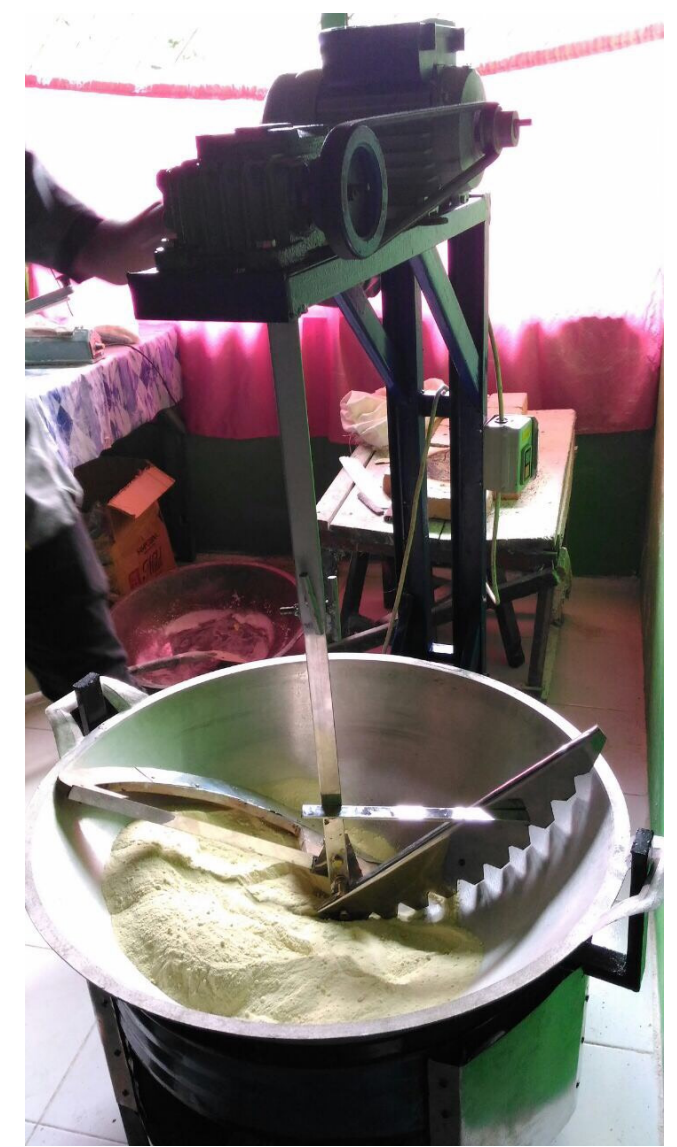

Gambar 2. Mesin Penyangraian

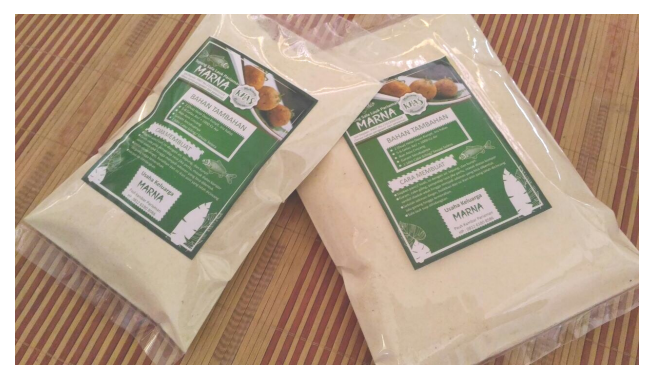

Gambar 3.Tampilan Kemasan Baru Tepung Sala Marna

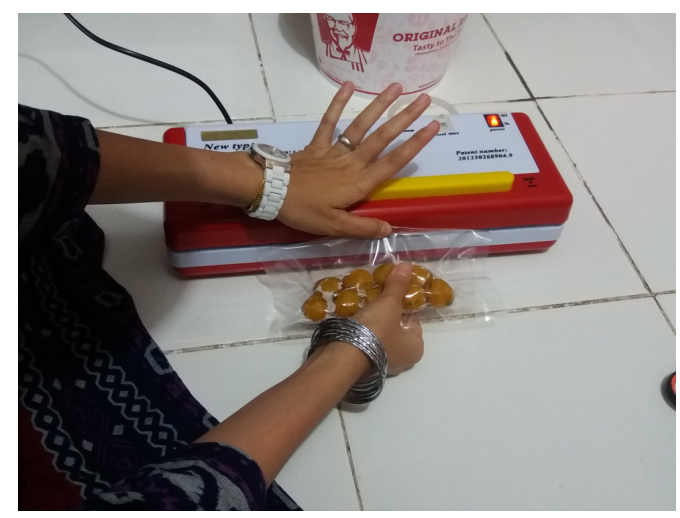

Gambar 4. Alat Pengemas Vacuum Sala Asli Piaman Ela 


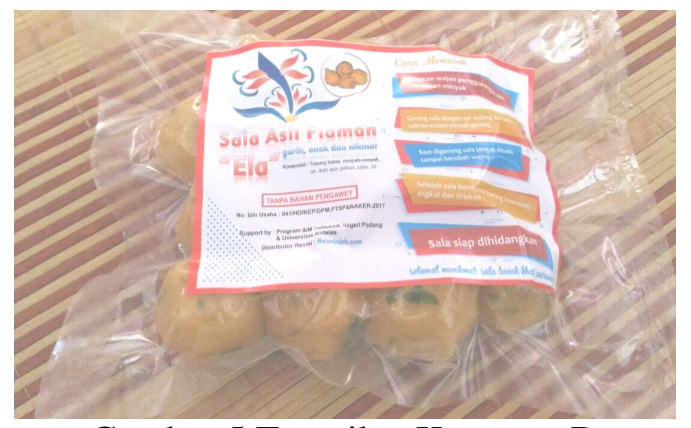

Gambar 5.Tampilan Kemasan Baru Sala Asli Piaman Ela

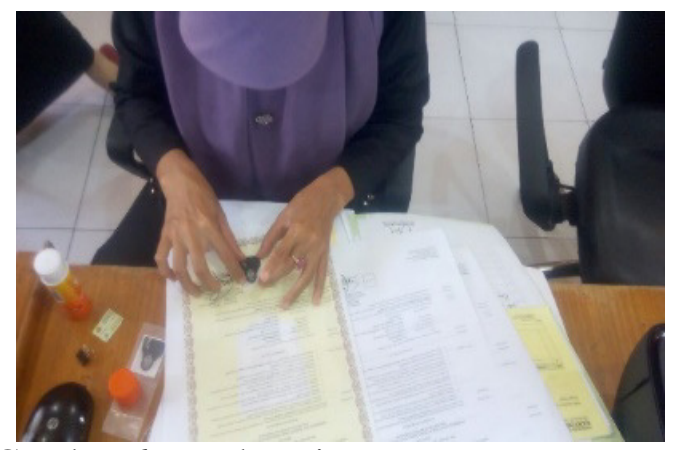

Gambar 6. Pendampingan Pengurusan PIRT

\section{KESIMPULAN}

Kesimpulan dari kegiatan ini adalah: a) telah berjalan sesuai dengan rencana dan harapan b) HPP untuk tepung sala "Marna" per kilogramnya adalah Rp. 16.664,-- per kg tepung sedangkan sala mentah pada "Sala Asli Piaman Ela adalah Rp. 19.200,- per kg.

\section{SARAN}

Kegiatan selanjutnya disarankan untuk melakukan pembinaan berkelanjutan pada manajemen keuangan dan perilaku produksi yang baik (GMP).

\section{UCAPAN TERIMAKASIH}

Penulis dan tim pengabdian mengucapkan terima kasih kepada DRPM Ditjen Penguatan Risbang, Dikti yang telah memberikan bantuan dana pelaksanaan kegiatan iptek bagi masyarakat serta kedua industri rumah tangga yang menjadi mitra pengabdian kali ini.

\section{REFERENSI}

[1] Kamsina, Anova IT. 2011. Pengaruh jenis tepung dan pengolahan ikan terhadap mutu tepung sala lauak. Jurnal Litbang Industri (1): 30-38

[2] Febriana A, Rachmawanti D, Anam C. 2014. Evaluasi kualitas gizi, sifat fungsional dan sifat sensoris sala lauak dengan variasi tepung beras sebagai alternatif makanan sehat. Jurnal Teknosains Pangan Vol 3 (2): 28-38

[3] Marliyanti SA, Hastuti D, Sinaga T. 2013. Eco-culinary tourism in Indonesia $d i$ dalam Teguh F, Avenzora R (ed). Ecotourism and sustainable development in Indonesia: the potentials, lessons and best practices. Jakarta. Kementerian Pariwisata dan Ekonomi Kreatif Republik Indonesia

[4] Assauri, S. 1999. Manajemen Produksi dan Operasi. FPUI. Jakarta.

[5] Pinasti, Margani. 2001. Penggunaan Informasi Akuntansi dalam Pengelolaan Usaha Para Pedagang Kecil di Pasar Tradisional Kabupaten Banyumas. Jurnal Ekonomi, Bisnis dan Akuntansi No. 1/Vol. 3/Mei

[6] Rudiantoro, Rizki \& Siregar, Sylvia Veronica. 2011. Kualitas Laporan Keuangan UMKM Serta Prospek Implementasi SAK ETAP. Makalah Simposium Nasional Akuntansi XIV. Aceh

[7] Sihite LB, Sudarno. 2012. Analisis Penentuan Harga Pokok Produksi pada Perusahaan Garam Beryodium (Studi Kasus pada UD Empat Mutiara. Diponegoro Journal of Accounting. Vol 1 No 2: 1-15

[8] Mulyadi. 2005. Akuntansi Biaya. Unit Penerbit dan Percetakan Akademi Manajemen Perusahaan YKPN. Yogyakarta. 